\title{
Cardiologic Long-Term Follow-Up of Patients Treated With Chest Radiotherapy: When and How?
}

\author{
Chiara Lestuzzi ${ }^{1 *}$, Maurizio Mascarin $^{2}$, Elisa Coassin ${ }^{2}$, Maria Laura Canale $^{3}$ and \\ Fabio Turazza ${ }^{4}$
}

${ }^{1}$ Azienda Sanitaria Friuli Occidentale (ASFO) Department of Cardiology, Cardiology and Cardio-Oncology Rehabilitation Service, Centro di Riferimento Oncologico (CRO), Istituto di Ricerca e Cura di Carattere Scientifico (IRCCS), Aviano, Italy, ${ }^{2}$ Adolescents and Young Adults (AYA) Oncology and Pediatric Radiotherapy Unit, Centro di Riferimento Oncologico (CRO), Istituto di Ricerca e Cura di Carattere Scientifico (IRCCS), Aviano, Italy, ${ }^{3}$ Cardiology Department, Azienda UsI Toscana Nord-Ovest, Ospedale Versilia, Camaiore, Italy, ${ }^{4}$ Cardiology Unit, Istituto Nazionale Tumori (INT), Istituto di Ricerca e Cura di Carattere Scientifico (IRCCS), Milan, Italy

OPEN ACCESS

Edited by:

Konstantinos Marmagkiolis, University of Texas MD Anderson

Cancer Center, United States

Reviewed by:

Zaza lakobishvili,

Clalit Health Services, Israel

Concetta Zito,

University of Messina, Italy

*Correspondence:

Chiara Lestuzzi

chiara.lestuzzi@asfo.sanita.fvg.it

Specialty section:

This article was submitted to

Cardio-Oncology,

a section of the journal

Frontiers in Cardiovascular Medicine

Received: 22 February 2021 Accepted: 27 September 2021 Published: 25 October 2021

Citation:

Lestuzzi C, Mascarin M, Coassin E,

Canale ML and Turazza F (2021) Cardiologic Long-Term Follow-Up of

Patients Treated With Chest Radiotherapy: When and How? Front. Cardiovasc. Med. 8:671001.

doi: 10.3389/fcvm.2021.671001
Introduction: Radiotherapy may cause valvular (VHD), pericardial, coronary artery disease (CAD), left ventricular dysfunction (LVD), arrhythmias. The risk of radiation induced heart disease $(R I H D)$ increases over time. The current guidelines suggest a screening for RIHD every 5 years in the long-term survivors who had been treated by chest RT.

Methods: We reviewed the clinical and instrumental data of 106 patients diagnosed with RIHD. In one group (Group A: 69 patients) RIHD was diagnosed in an asymptomatic phase through a screening with ECG, echocardiogram and stress test. A second group (37 patients) was seen when RIHD was symptomatic. We compared the characteristics of the two groups at the time of RT, of RIHD detection and at last follow-up.

Results: Overall, 64 patients (60\%) had CAD (associated to other RIHD in 18); 39 (36.7\%) had LVD (isolated in 20); 24 (22.6\%) had VHD (isolated in 10 cases). The interval between the last negative test and the diagnosis of moderate or severe RIHD was $<5$ years in 26 patients, and $<4$ years in 18. In group A, 63\% of the patients with CAD had silent ischemia. The two groups did not differ with regard to type of tumor, cardiovascular risk factors, use of anthracycline-based chemotherapy, age at RT treatment, radiation dose and interval between RT and toxicity detection. The mean time from RT and RIHD was 16 years in group $A$ and 15 in group $B$. Interventional therapy at RIHD diagnosis was more frequent in group B (54 vs. 30\%, $p<0.05$ ). At last follow-up, 27 patients had died (12 of cancer, 9 of cardiac causes, 6 of other causes); mean ejection fraction was $60 \%$ in group $A$ and $50 \%$ in group $B(p<0.01)$. Patients with ejection fraction $\leq 50 \%$ were $14.5 \%$ in group $A$ and $40 \%$ in group $B(p<0.01)$.

Conclusions: Clinically relevant RHHD become evident at a mean interval of 16 years after RT. The most frequent clinical manifestations are CAD and LVD. RIHD diagnosis in asymptomatic patients may preserve their cardiac function with timely interventions. We suggest -after 10 years from radiotherapy- a screening every 2-3 years.

Keywords: radiotherapy-adverse effects, long term survivors, lymphoma, radiation-induced heart disease (RIHD), coronary artery disease, valvular heart disease (VHD), left ventricular dysfunction (LVD), cardiotoxicity 


\section{INTRODUCTION}

Chest radiotherapy (RT) for mediastinal or lung tumors or also breast cancer (mostly left-sided), is associated with long-term cardiac adverse effects, namely coronary artery disease (CAD), valvular heart disease (VHD), left ventricular dysfunction (LVD), and pericardial disease $(1,2)$. The risk of radiation-induced heart disease (RIHD) increases over time: the cumulative incidence of RIHD requiring intervention, 20 years after mediastinal irradiation for Hodgkin's lymphoma, is $16 \%(3,4)$. Survivors of childhood and adolescent cancer treated with RT, compared to their siblings, have a 5-6-fold risk of myocardial infarction, pericardial disease, or valvular abnormalities after 30 years of age (5). Cardiologic surveillance is, therefore, recommended every 5 years for cancer survivors treated with chest RTs, mostly for those treated during childhood, or when symptoms appear (6). We will analyze this approach on the basis of our experience at the CRO (National Cancer Institute of Aviano), in the cardio-oncology and long-term survivors clinic.

\section{MATERIALS AND METHODS}

We reviewed the clinical and instrumental data of 106 patients under care at the National Cancer Institute (CRO) of Aviano and who were diagnosed with RIHD. The study was approved by the internal review board. In one group (Group A: 69 patients), RIHD was diagnosed in an asymptomatic phase; these pertained to a group of 321 patients undergoing regular screening every 2-5 years with: clinical cardiologic examination, resting ECG, resting echocardiogram (M-mode, two-dimensional, and Doppler), and stress test for a period of 2-44 years (mean 17, median 16), or who were seen occasionally when referred to our outpatient cardiology clinic for routine examinations before surgery. A second group (Group B: 37 patients) was seen, due to complaints of symptoms related to their RIHD.

CAD was diagnosed in the presence of acute coronary syndrome or myocardial infarction or on the basis of provocative tests (treadmill or bicycle stress test, stress echocardiography, myocardial scintigraphy), and coronary angiography (7). LVD was diagnosed in the presence of $a \geq 15 \%$ drop in left ventricular ejection fraction (LVEF) from baseline to an absolute value of $\leq 53 \%$, or a $>10 \%$ drop to a value $\leq 50 \%(8,9)$. Since a baseline echocardiogram before RT was not always available for patients treated before 1990, and in those treated in different hospitals, a LVEF of $<45 \%$ was considered diagnostic of hypokinetic cardiomyopathy (10). The severity of valvular heart disease was assessed according to current guidelines at the time of the echocardiographic evaluation and integrated with cardiac catheterization and/or surgical data in patients who underwent cardiac surgery (11-13). We considered moderate to severe mitral regurgitation, aortic regurgitation, and/or aortic stenosis as being clinically relevant and considered VHD secondary to RT in the absence of other conditions (e.g., pre-existing valve abnormalities, severe mitral valve prolapse, clinical history of rheumatic heart disease, or bacterial endocarditis) that could be a possible cause.

\section{STATISTICAL ANALYSIS}

Given the descriptive aim of the registry, no formal statistical design was set up. Descriptive data are presented as a percentage of the entire number of patients. Time to RIDH was calculated from radiotherapy to the first evidence of cardiac toxicity, while follow-up time was calculated from the time of RIDH to the last visit or death. Continuous variables were expressed as the mean \pm standard deviation of and their differences were tested for significance with the Student's $t$-test. The association between clinical parameters were calculated using contingency table methods and tested for significance using the Pearson's chi-square test. All significance levels were set at a 0.05 value, and $p$-values were two-sided. SPSS software (version 19.00, SPSS, Chicago) was used for all statistical analysis.

\section{RESULTS}

\section{Demographics and Treatment Data}

The patients were 34 males and 72 females, 8-67 years of age at the time of RT, with 78 who received mediastinal RTs for Hodgkin's lymphoma $(n=54)$ or Non-Hodgkin's lymphoma ( $n=24$ ), and 27 chest RTs for breast cancer (26 left-side, 1 right-side, including sternum in the RT plan). Cardiovascular risk factors included diabetes in 8 patients, dyslipidemia in 31 , hypertension in 12 , smoking habits in 4 , and family history of CAD in 20. For all patients, an attempt was made to prevent all modifiable cardiovascular risk factors, such as encouraging them to perform regular physical activity, to avoid or stop smoking, and to regularly check blood glucose and lipids (14). To patients with hypertension, diabetes, and dyslipidemia detected during follow-up, appropriate medical therapy was also prescribed: antidiabetics, statins and/or angiotensin inhibitors or beta-blockers (according to heart rate), and acetylsalicylic acid. In 6 patients, the total radiotherapy dose delivered was unknown. In the others, it ranged from 15 to $60 \mathrm{~Gy}$; a $>35 \mathrm{~Gy}$ dose-which doubles the risk of RIHD compared to doses of 20-30 Gy (15) - was administered to 77 patients. Anthracycline-based chemotherapy (before or after RT) was given to 68 patients (Table 1). Females were represented more in the asymptomatic group (75 vs. $54 \%$, $p<0.05)$. The two groups did not differ with regard to type of tumor, cardiovascular risk factors, use of anthracycline-based chemotherapy, age at RT, and radiation dose (Table 1). The RT techniques changed over time (with the extended mantle field RT progressively replaced in the 1990s by modern techniques, such as Involved Fields Radiotherapy IFRT, which significantly reduce radiation burden to the heart and the risk of RIHD) (1621). We, therefore, also took this variable into consideration. The patients were treated between 1974 and 2010: 79 up to and 27 after 1999. The proportion of patients treated before 2000 (when modern techniques were introduced as standard treatment in our hospital), were similar in the two groups (Table 1). The only difference between the two was an increased prevalence of females in the asymptomatic group. 
TABLE 1 | Baseline characteristics of the entire study group and of the two groups.

\begin{tabular}{|c|c|c|c|c|}
\hline & $\begin{array}{c}\text { Total } \\
(n=106)\end{array}$ & $\begin{array}{l}\text { Asymptomatic } \\
\text { group } \\
(n=69)(\%)\end{array}$ & $\begin{array}{l}\text { Symptomatic } \\
\text { group } \\
(n=37)(\%)\end{array}$ & $p$ \\
\hline Males & 34 & 17 (25\%) & 17 (46\%) & $<0.05$ \\
\hline Females & 72 & 52 (75\%) & 20 (54\%) & \\
\hline Hodgkin's & 54 & 33 (48\%) & $21(57 \%)$ & NS \\
\hline Non-Hodgkin's & 24 & $15(22 \%)$ & $9(24 \%)$ & NS \\
\hline Breast cancer & 27 & $20(29 \%)$ & $7(19 \%)$ & NS \\
\hline Diabetes & 8 & $4(5.8 \%)$ & $4(11 \%)$ & NS \\
\hline Dyslipidemia & 31 & 19 (27.5\%) & $12(32 \%)$ & NS \\
\hline Hypertension & 12 & 7 (10\%) & 5 (13.5\%) & NS \\
\hline Active smoker & 4 & $1(1.5 \%)$ & $3(8 \%)$ & NS \\
\hline Anthracyclines & 79 & 52 (75\%) & 27 (73\%) & NS \\
\hline Total dose $\geq 35$ Gy $^{*}$ & $84 / 99^{*}$ & $56 / 63^{*}(88 \%)$ & $28 / 36^{\star}(78 \%)$ & NS \\
\hline \multirow[t]{2}{*}{ Treated before 2,000 } & 79 & $51(74 \%)$ & $28(76 \%)$ & NS \\
\hline & Mean \pm SD & Mean \pm SD & Mean \pm SD & \\
\hline Age at RT (years) & $38 \pm 14.7$ & $39 \pm 15$ & $35 \pm 15$ & NS \\
\hline Radiation dose (Gy) & $40 \pm 8$ & $41 \pm 8$ & $39 \pm 9$ & NS \\
\hline $\begin{array}{l}R T \text {, Radiotherapy; Gy, } \\
\text { Standard Deviation. } \\
{ }^{\star} \text { Data of } 7 \text { patients are } \\
\text { complete information. }\end{array}$ & $\begin{array}{l}\text { Grays; } R I H D \text {, } \\
\text { nissing; percenta }\end{array}$ & $\begin{array}{l}\text { Radiation Induce } \\
\text { age calculated on th }\end{array}$ & ed Heart Diseas & $\begin{array}{l}\text { se; } S D \text {, } \\
\text { ents with }\end{array}$ \\
\hline
\end{tabular}

\section{Radiation-Induced Heart Disease}

Overall, 64 patients (60\%) had CAD (isolated in 46, associated to other cardiac diseases in 18); 39 patients (36.7\%) had LVD (isolated in 20); 24 (22.6\%) had valvular heart disease (isolated in 10 cases). Among patients in the asymptomatic group who had CAD diagnosed with a stress test, 21/32 (63\%) had silent ischemia. Isolated LVD was more frequent in the asymptomatic group (23vs. 11\%), but the difference was not statistically significant. On the contrary, the association between LVD and myocardial ischemia was significantly more frequent in the symptomatic group (22 vs. $3 \%, p<0.01$ ). Isolated VHD and pericardial constriction were only detected in asymptomatic patients, while the association of cardiac ischemia and VHD, with or without LVD, was only observed in the symptomatic group. However, due to the small number of cases, the difference was not statistically significant (Table 2). In 17 patients with different manifestations of RIHD, a second or third toxicity was diagnosed, 1-18 (median of 7) years apart. The first diagnosis of RIHD was reached at a mean and median time of 16 years from RT (range 0-35 years), without any significant difference between the two groups. RIHD was diagnosed in 5 patients ( 1 in the asymptomatic group, 4 in the symptomatic group) in the first year after RT. All had been previously treated with anthracyclines, had a normal EF after chemotherapy, and developed LVD shortly after a mediastinal RT with $\geq 40 \mathrm{~Gy}$. We, therefore, considered that, although these patients might have had subclinical anthracycline myocardial damage, the role of RT was relevant. The mean and median ages at the time of the first clinical evidence of RIHD were 54 and 52 years, respectively. Thirty-six patients presented one
TABLE 2 | Characteristics of the patients at time of detection of radiation induced heart disease.

\begin{tabular}{|c|c|c|c|c|}
\hline & $\begin{array}{c}\text { Total } \\
(n=106)(\%)\end{array}$ & $\begin{array}{l}\text { Asymptomatic } \\
\text { group } \\
(n=69)\end{array}$ & $\begin{array}{l}\text { Symptomatic } \\
\text { group } \\
(n=37)\end{array}$ & $p$ \\
\hline $\begin{array}{l}\text { Left ventricular } \\
\text { dysfunction (LVD) }\end{array}$ & 20 (19\%) & $16(23 \%)$ & $4(11 \%)$ & NS \\
\hline Cardiac ischemia & $46(43 \%)$ & $33(48 \%)$ & $13(35 \%)$ & NS \\
\hline Valvular disease & $10(9 \%)$ & $10(14.5 \%)$ & 0 & NS \\
\hline $\begin{array}{l}\text { Pericardial } \\
\text { constriction }\end{array}$ & $1(0.9 \%)$ & $1(1.5 \%)$ & 0 & NS \\
\hline LVD + ischemia & $10(9 \%)$ & $2(3 \%)$ & 8 (22\%) & 0.01 \\
\hline $\begin{array}{l}\text { Valvular disease + } \\
\text { constriction }\end{array}$ & $1(0.9 \%)$ & 0 & $1(3 \%)$ & NS \\
\hline $\begin{array}{l}\text { LVD + valvular } \\
\text { disease }\end{array}$ & $5(4.7 \%)$ & $2(3 \%)$ & $3(8 \%)$ & NS \\
\hline $\begin{array}{l}\text { Ischemic and } \\
\text { valvular disease }\end{array}$ & $4(4 \%)$ & 0 & $4(11 \%)$ & NS \\
\hline \multirow{2}{*}{$\begin{array}{l}\text { LVD + ischemia + } \\
\text { valvular disease }\end{array}$} & $4(4 \%)$ & 0 & $4(11 \%)$ & NS \\
\hline & $\begin{array}{l}\text { Min, Max, } \\
\text { Median }\end{array}$ & Mean \pm SD $^{*}$ & Mean \pm SD* $^{\star}$ & \\
\hline $\begin{array}{l}\text { Age at first RIHD } \\
\text { detection (years) }\end{array}$ & $22,82,52$ & $55 \pm 12$ & $52 \pm 13$ & $N S^{*}$ \\
\hline Time from RT (years) & $0,35,16$ & $16 \pm 9$ & $15 \pm 9$ & $\mathrm{NS}^{*}$ \\
\hline $\begin{array}{l}\text { Interval between a } \\
\text { normal test and } \\
\text { RIHD }\end{array}$ & $0,23,3$ & $4 \pm 3.7$ & $3 \pm 3.4$ & $N S^{*}$ \\
\hline
\end{tabular}

LVD, Left Ventricular Dysfunction; PCI, Percutaneous Coronary Intervention; RT, Radiotherapy; SD, Standard deviation; NS, non-significant.

${ }^{\star} P$ calculated on the mean $\pm S D$.

or more normal or minimally altered tests relevant to the specific RIHD (e.g., an echocardiogram for LVD and VHD, a provocative test for CAD), obtained before the diagnosis of moderate to severe disease (Figure 1). The interval between the last negative test and the diagnosis of moderate or severe RIHD was 0 (2 patients experienced an acute myocardial infarction a few months after a negative treadmill stress test) to 7 years (mean and median time of 3 years). In 26 patients (72\%), the interval was $<5$ years; in $18(50 \%)$ it was < 4 years. Among patients with CAD, 22 had a previous negative stress test performed $0-6$ years before (at a median time of 3 years); 3 who presented an acute myocardial infarction had a negative stress test within 2 years before the myocardial infarction.

\section{Treatment and Follow-Up}

After diagnosis, each patient was treated according to type and severity of their disease and symptoms. Cardiac surgery (either valvular or coronary artery graft), or interventions, such as Transcatheter Valve Replacement (TAVR) or Percutaneous Coronary Intervention (PCI), were indicated in 41 patients (38.7\%). The need of interventional therapy was more frequently considered in the symptomatic group (54 vs. 30\%, $p<0.05$ ). After diagnosis, 11 patients ( 7 in the asymptomatic group and 4 in the symptomatic group) were lost to follow-up. For those 


\section{A}

\section{February 2014}

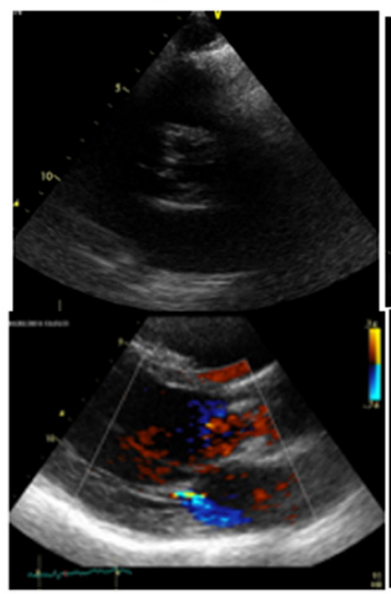

B

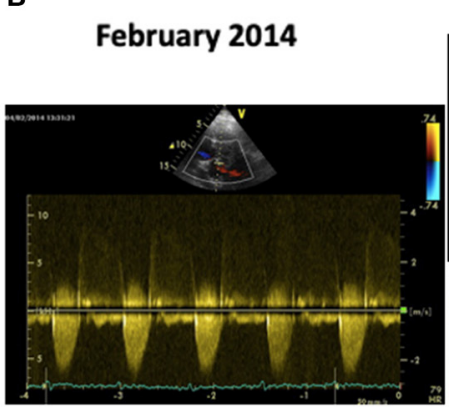

February 2018

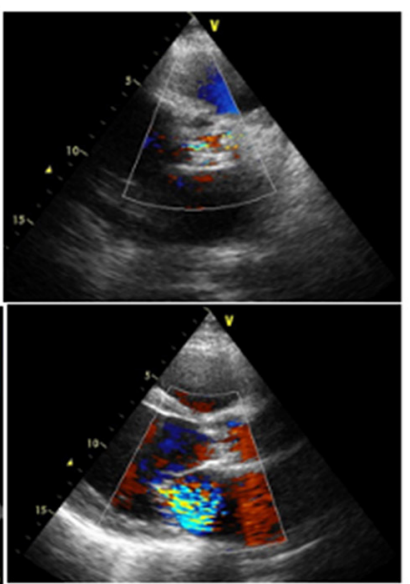

February 2018

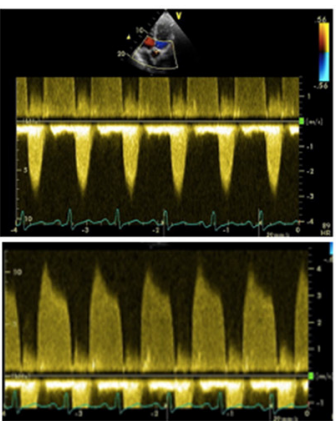

C
February 2014

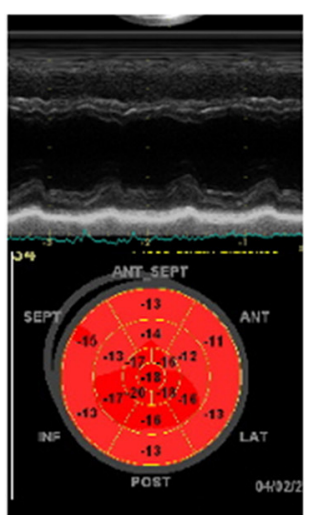

February 2018

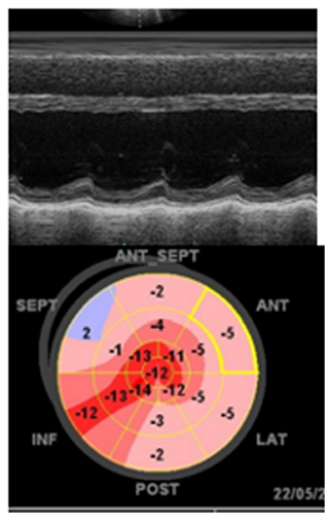

FIGURE 1 | Echocardiograms of a patient treated with anthracyclines chemotherapy and mediastinal RT in 1999, at age 19. He underwent a cardiologic follow-up every 2-3 years. In February, 2014 (images on the left) the echocardiogram detected the new appearance of mild aortic and mitral dysfunction (A,B); the left ventricular (LV) function and Global Longitudinal Strain (GLS) were normal (C); a stress test was negative. We planned yearly check-up, but the patient, who felt completely asymptomatic, skipped the appointments. In February 2018, at age 38, he suddenly experienced a

(Continued)
FIGURE 1 | congestive heart failure. The echocardiogram (images on the right) showed: calcific aortic stenosis, severe mitral regurgitation (A); severe aortic stenosis and moderate aortic regurgitation (B); severe LV dysfunction and abnormal GLS (C). At coronary angiography a 70\% stenosis of the left anterior descending coronary artery was detected.

in the asymptomatic group, a mean follow-up of $10 \pm 5$ years was available; for those in the symptomatic group, the available follow-up was $7 \pm 4$ years. Overall, 27 patients died (29\% of the asymptomatic group and $20 \%$ of the symptomatic groupTable 3). The causes of death were cardiac-related (heart failure or acute myocardial infarction) in 9 cases, cancer progression or second/third cancer diagnosis in 12, sepsis in 2 cases, and unknown in 4 . The left ventricular EF at the last follow-up was $60 \pm 10 \%$ in the asymptomatic group and $50 \pm 13 \%$ in the symptomatic group $(p<0.01)$. Patients with an $\mathrm{EF}<50 \%$ were $14.5 \%$ in the asymptomatic group and $40 \%$ in the symptomatic group $(p<0.01)$.

\section{DISCUSSION}

Our experience confirms previous reports assessing that the prevalence of moderate to severe valvular disease, CAD, and LVD in patients treated with mediastinal or chest RT is high and increases with time after irradiation (22-26). According to these observations, surveillance should be lifelong.

Our retrospective study included patients of different ages, with different tumors and under various radiation treatments. These differences might actually influence the incidence of RIHD in different subgroups (19). The number of patients was too low to allow for a comparison between mediastinal and breast RT, and the aim of the study was only to assess what the best approach for screening might be in patients at risk of RIHD in the real world, in a cardiology clinic, or in general clinical practice.

As previously reported, RT is an independent risk factor of $\mathrm{CAD}$, and the disease is often asymptomatic: this warrants an active screening process $(27,28)$. Autonomic dysfunction, which is frequent after RT, is similar to the cardiac autonomic cardiopathy observed in diabetes, possibly secondary to direct cardiac nerve damage by RT, and might explain the absence of angina (29-31). In fact, most of our patients with CAD who were in the screening group had silent ischemia, and those in the symptomatic group had a higher prevalence of LVD (with dyspnea as a prevalent symptom). The problem of silent ischemia is particularly relevant because patients have no warning symptoms during physical exertion, and the first symptomatic episode may be an acute myocardial infarction, or an ischemic cardiomyopathy, which may lead to a chronic anatomic and functional defect (32). Therefore, regular screening for cardiac ischemia is highly recommended, regardless of the presence or absence of angina. Screening may be performed as it is for CAD in diabetic patients, using either a physical or pharmacological stress test (preferably with imaging, such as echo-stress, or with myocardial scintigraphy), computed 
TABLE 3 | Treatments and outcome after diagnosis.

\begin{tabular}{|c|c|c|c|c|c|}
\hline & & Total $(n=106)(\%)$ & Asymptomatic group $(n=69)$ & Symptomatic group $(n=37)$ & $p$ \\
\hline \multicolumn{2}{|c|}{ Cardiac surgery or $\mathrm{PCl}$} & $41(38.7 \%)$ & $21(30 \%)$ & $20(54 \%)$ & 0.025 \\
\hline \multicolumn{2}{|c|}{ Mean follow-up after diagnosis (years) } & & $10 \pm 5$ & $7 \pm 4$ & \\
\hline \multicolumn{2}{|l|}{ Death } & 27 & $20(29 \%)$ & 7 (20\%) & NS \\
\hline \multirow[t]{3}{*}{ Cause of death } & Cardiac & 9 & 1 & 8 & \\
\hline & Cancer & 12 & 4 & 8 & \\
\hline & Others/unknown & 6 & 3 & 3 & \\
\hline \multicolumn{3}{|c|}{ EF at last follow-up (mean value \pm SD) } & $60 \pm 10$ & $50 \pm 13$ & 0.024 \\
\hline \multicolumn{2}{|c|}{ Patients with EF <50\% at last follow-up } & 25 (23.6\%) & $10(14.5 \%)$ & $15(40 \%)$ & 0.01 \\
\hline
\end{tabular}

EF, Ejection Fraction; PCI, Percutaneous Coronary Intervention; SD, Standard Deviation.

tomography calcium score, or other methods (according to the availability of the tests in a given center), as well as balancing diagnostic utility, and cost and risk for the patient (33-36).

The time to progression of VHD and CAD was short in our patients, in contrast with a paper by Donnellan, who found a similar rate of progression in the aortic stenosis gradient in patients with or without previous RT (37). However, follow-up in the Donnellan study was shorter (lasting an average of 3.6 years) than in the present study, and the RT patients still had a more severe change in the aortic valve area and a significantly shorter time from the baseline echocardiogram to symptom onset and aortic valve replacement (AVR). The progression from aortic sclerosis to severe calcific stenosis involves genetic factors, lipoprotein deposition and oxidation, and chronic inflammation. The use of aggressive therapy to lower blood pressure, blood lipids, and to contrast chronic inflammation may slow down this process (38-43). According to our experience, patients who had any sort of aortic or coronary calcification detected during screening (even if subclinical), should undergo a strict follow-up (yearly or every other year), since the disease might worsen in a short period of time.

The higher prevalence of symptomatic patients undergoing valve replacement or revascularization in the present study is explained by the fact that, among the asymptomatic patients, major interventions were only proposed to those with severe disease or those at a high risk of clinical instability (e.g., critical stenosis of a main coronary artery or very severe aortic stenosis), while aggressive medical therapy with strict follow-up and additional tests (such as stress echocardiography or myocardial scintigraphy) were proposed to the others, in order to delay the need for cardiac surgery, TAVR, and/or PCI, which has often been reported to be technically difficult, risky, and with less probability of long-term success in these types of patients (44-51). Another reason to postpone surgery in the asymptomatic patients is that CAD and VHD may often progress at a different rate, requiring further interventions years apart, and we attempted to prevent resurgery (52).

In terms of EF, the better outcome at follow-up of the asymptomatic patients could be explained by the fact that a timely therapeutic intervention (lowering blood pressure, prescribing statins, anti-inflammatory medication, and anti-ischemic therapy in these patients if needed, as well as performing cardiac surgery or percutaneous interventions for severe valvular disease or CAD) prevented myocardial infarctions and adverse cardiac remodeling, secondary to cardiac ischemia and myocardial fibrosis in patients with $\mathrm{CAD}$, or to pressure overload in patients with VHD (53-56). Therefore, our experience reinforces the concept that RIHD should be recognized and treated before the symptomatic phase. A major problem, which is mostly detected in younger patients, is the fact that they are often reluctant to consider their cardiovascular risk and, therefore, might not adhere to prescriptions, as a reaction to post-traumatic stress, which may lead to denial (57-59).

With regard to the timing of screening tests, it is wellknown (through large cohort studies) that the incidence of symptomatic RIHD is very low in the first 10 years after RT and increases rapidly afterwards. This is not limited to patients treated in adult age (who could have a risk linked to their age) but also to those treated in childhood who develop $\mathrm{CAD}$ or VHD at a relatively young age. Nevertheless, current guidelines suggest screening every 5 years or when symptoms develop, regardless of the time from RT. According to our experience, an interval of 5 years is too long, since many patients might progress from mild to severe disease during this period, possibly with the event of an acute myocardial infarction or sudden death. Moreover, symptoms such as dyspnea (secondary to VHD or angina equivalent) may be under-assessed and misinterpreted in patients with chronic lung dysfunction, as patients treated with chest RT frequently are (mostly if chemotherapy with bleomycin/or anthracycline were added) (60-63).

Along with regular screening tests, special attention must be given to these patients in relation to their adherence to suggested lifestyles and pharmacologic prescriptions. This behavior must be constantly reinforced. Since oncologists often dismiss patients from follow-up after a time span of 10-15 years from complete recovery, this should be carried out by other physicians: usually general practitioners who tend to their patient for all their various conditions, and cardiologists who conduct the follow-ups. Communication must be tailored to the particular psychological attitude of long-term cancer survivors (64). 


\section{CONCLUSIONS}

RIHD is an elusive clinical entity in the pre-symptomatic phase and can worsen dramatically in a short period of time. The timely recognition of subclinical RIHD and promptly prescribed therapies may improve the long-term outcome of patients who, after recovering from cancer, are at risk of cardiac events. Screening tests should be more frequent (every 2 or 3 years) after 10 years from RT, and even more frequent (on a yearly basis) in patients with a possible high risk of progression (initial valve disease, coronary calcification, moderate to high risk of CAD). General practitioners and general cardiologists (who may see patients for reasons that do not depend on their cancer history but just for routine check-ups), should be aware of the risk of RIHD, of its often elusive clinical presentation, of the need for and method of screening it, and should care for the many patients who are not followed by a long-term survivors clinic or by an oncocardiologist.

\section{DATA AVAILABILITY STATEMENT}

The raw data supporting the conclusions of this article will be made available by the authors, without undue reservation.

\section{REFERENCES}

1. Desai MY, Windecker S, Lancellotti P, Bax JJ, Griffin BP, Cahlon O, et al. Prevention, diagnosis, and management of radiation-associated cardiac disease: JACC scientific expert panel. J Am Coll Cardiol. (2019) 74:905-27. doi: 10.1016/j.jacc.2019.07.006

2. Atkins KM, Rawal B, Chaunzwa TL, Lamba N, Bitterman DS, Williams CL, et al. Cardiac radiation dose, cardiac disease, and mortality in patients with lung cancer. J Am Coll Cardiol. (2019) 73:2976-87. doi: 10.1016/j.jacc.2019.03.500

3. Donnellan E, Jellis CL, Griffin BP. Radiation-associated cardiac disease: from molecular mechanisms to clinical management. Curr Treat Options Cardiovasc Med. (2019) 21:22. doi: 10.1007/s11936-019-0726-3

4. Galper SL Yu JB, Mauch PM, Strasser JF, Silver B, Lacasce A, et al. Clinically significant cardiac disease in patients with Hodgkin lymphoma treated with mediastinal irradiation. Blood. (2011) 117:412-8. doi: 10.1182/blood-2010-06-291328

5. Mulrooney DA, Yeazel MW, Kawashima T, Mertens AC, Mitby P, Stovall $\mathrm{M}$ et al. Cardiac outcomes in a cohort of adult survivors of childhood and adolescent cancer: retrospective analysis of the childhood cancer survivor study cohort. BMJ. (2009) 339:b4606. doi: 10.1136/bmj.b4606

6. Armenian SH, Hudson MM, Mulder RL, Chen MH, Constine LS, Dwyer M, et al. International late effects of childhood cancer guideline harmonization group. Recommendations for cardiomyopathy surveillance for survivors of childhood cancer: a report from the international late effects of childhood cancer guideline harmonization group. Lancet Oncol. (2015) 3:e123-36. doi: 10.1016/S1470-2045(14)70409-7

7. Fihn SD, Blankenship JC, Alexander KP, Bittl JA, Byrne JG, Fletcher BJ, et al. 2014 ACC/AHA/AATS/PCNA/SCAI/STS Focused update of the guideline for the diagnosis and management of patients with stable ischemic heart disease: a report of the American college of cardiology/American heart association task force on practice guidelines, and the American association for thoracic surgery, preventive cardiovascular nurses association, society for cardiovascular angiography and interventions, and society of thoracic surgeons. J Am Coll Cardiol. (2014) 64:1929-49. doi: 10.1161/CIR.0000000000000095

8. Curigliano G, Cardinale D, Suter T, Plataniotis G, de Azambuja E, Sandri MT, et al. Cardiovascular toxicity induced by chemotherapy, targeted agents and

\section{ETHICS STATEMENT}

The studies involving human participants were reviewed and approved by the Comitato Etico Unico Regionale (CEUR) Friuli Venezia Giulia. Written informed consent for participation was not required for this study in accordance with the national legislation and the institutional requirements.

\section{AUTHOR CONTRIBUTIONS}

CL, MM, and EC planned the study, recruited and followed the patients, and wrote the paper. MC performed the statistical analysis and contributed in writing the paper. FT contributed in writing the paper. All authors contributed to the article and approved the submitted version.

\section{ACKNOWLEDGMENTS}

We would like to thank Ms. Leila Myftija for her assistance in editing the paper. We are grateful to the Italian Ministry of Health - Ricerca Corrente for the financial support in publishing this paper.

radiotherapy: ESMO clinical practice guidelines. Ann Oncol. (2012) 23(Suppl. 7):vii155-66. doi: 10.1093/annonc/mds293

9. Zamorano JL, Lancellotti P, Rodriguez Muñoz D, Aboyans V, Asteggiano R, Galderisi M, et al. 2016 ESC Position paper on cancer treatments and cardiovascular toxicity developed under the auspices of the ESC committee for practice guidelines: the task force for cancer treatments and cardiovascular toxicity of the European society of cardiology (ESC). Eur J Heart Fail. (2017) 19:9-42. doi: 10.1002/ejhf.654

10. Pinto YM, Elliott PM, Arbustini E, Adler Y, Anastasakis A, Böhm M, et al. Proposal for a revised definition of dilated cardiomyopathy, hypokinetic nondilated cardiomyopathy, and its implications for clinical practice: a position statement of the ESC working group on myocardial and pericardial diseases. Eur Heart J. (2016) 37:1850-8. doi: 10.1093/eurheartj/ehv727

11. Baumgartner H. Chair, Hung J Co-Chair, Bermejo J, Bermejo J, Chambers JB, Edvardsen T, et al. Recommendations on the echocardiographic assessment of aortic valve stenosis: a focused update from the European association of cardiovascular imaging and the American society of echocardiography. Eur Heart J Cardiovasc Imaging. (2017) 18:254-75. doi: 10.1093/ehjci/ jew335

12. Zoghbi WA, Enriquez-Sarano M, Foster E, Grayburn PA, Kraft CD, Levine RA, et al. American society of echocardiography. Recommendations for evaluation of the severity of native valvular regurgitation with twodimensional and doppler echocardiography. J Am Soc Echocardiogr. (2003) 16:777-802. doi: 10.1016/S0894-7317(03)00335-3

13. Lancellotti P, Tribouilloy C, Hagendorff A, Popescu BA, Edvardsen T, Pierard LA, et al. Scientific document committee of the European association of cardiovascular imaging. Recommendations for the echocardiographic assessment of native valvular regurgitation: an executive summary from the European association of cardiovascular imaging. Eur Heart $J$ Cardiovasc Imaging. (2013) 14:611-44. doi: 10.1093/ehjci/jet105

14. Chen Y, Chow EJ, Oeffinger KC, Border WL, Leisenring WM, Meacham LR, et al. Traditional cardiovascular risk factors and individual prediction of cardiovascular events in childhood cancer survivors. J Natl Cancer Inst. (2020) 112:256-65. doi: 10.1093/jnci/djz108

15. Schellong G, Riepenhausen M, Bruch C, Kotthoff S, Vogt J, Bölling T, et al. Late valvular and other cardiac diseases after different doses of mediastinal radiotherapy for Hodgkin disease in children and adolescents: report from 
the longitudinal GPOH follow-up project of the German-Austrian DAL-HD studies. Pediatr Blood Cancer. (2010) 55:1145-52. doi: 10.1002/pbc.22664

16. Engert A, Schiller P, Josting A, Herrmann R, Koch P, Sieber M, et al. Involved-field radiotherapy is equally effective and less toxic compared with extended-field radiotherapy after four cycles of chemotherapy in patients with early-stage unfavorable Hodgkin's lymphoma: results of the HD8 trial of the German Hodgkin's lymphoma study group. J Clin Oncol. (2003) 21:3601-8. doi: 10.1200/JCO.2003.03.023

17. Vordermark D, Seufert I, Schwab F, Kölbl O, Kung M, Angermann C, et al. 3-D reconstruction of anterior mantle-field techniques in Hodgkin's disease survivors: doses to cardiac structures. Radiat Oncol. (2006) 1:10. doi: 10.1186/1748-717X-1-10

18. Koh ES, Tran TH, Heydarian M, Sachs RK, Tsang RW. Brenner DJ, et al. A comparison of mantle versus involved-field radiotherapy for Hodgkin's lymphoma: reduction in normal tissue dose and second cancer risk. Radiat Oncol. (2007) 2:13. doi: 10.1186/1748-717X-2-13

19. Lewis GD, Farach A. Cardiovascular toxicities of radiation therapy. Methodist Debakey Cardiovasc J. (2019) 15:274-81. doi: 10.14797/mdcj-15-4-274

20. Niska JR, Thorpe CS, Allen SM, Daniels TB, Rule WG, Schild SE, et al. Radiation and the heart: systematic review of dosimetry and cardiac endpoints. Expert Rev Cardiovasc Ther. (2018) 16:931-50. doi: 10.1080/14779072.2018.1538785

21. Eloranta S, Lambert PC, Sjöberg J, Andersson TM, Björkholm M, Dickman PW. Temporal trends in mortality from diseases of the circulatory system after treatment for Hodgkin lymphoma: a population-based cohort study in Sweden (1973 to 2006). J Clin Oncol. (2013) 31:1435-41. doi: 10.1200/JCO.2012.45.2714

22. van Nimwegen FA, Schaapveld $M$, Janus $C P$, Krol AD, Petersen EJ, Raemaekers JM, et al. Cardiovascular disease after Hodgkin lymphoma treatment: 40-year disease risk. JAMA Intern Med. (2015) 175:1007-17. doi: 10.1001/jamainternmed.2015.1180

23. Bijl JM, Roos MM, van Leeuwen-Segarceanu EM, Vos JM, Bos WW, Biesma $\mathrm{DH}$, et al. Assessment of valvular disorders in survivors of Hodgkin's lymphoma treated by mediastinal radiotherapy \pm chemotherapy. Am J Cardiol. (2016) 117:691-6. doi: 10.1016/j.amjcard.2015.11.027

24. Lipshultz SE, Adams MJ, Colan SD, Constine LS, Herman EH, Hsu DT, et al. Long-term cardiovascular toxicity in children, adolescents, and young adults who receive cancer therapy: pathophysiology, course, monitoring, management, prevention, and research directions: a scientific statement from the American heart association. Circulation. (2013) 128:1927-95. doi: 10.1161/CIR.0b013e3182a88099

25. Darby SC, Ewertz M, McGale P, Bennet AM, Blom-Goldman U, Brønnum $\mathrm{D}$, et al. Risk of ischemic heart disease in women after radiotherapy for breast cancer. N Engl J Med. (2013) 368:987-98. doi: 10.1056/NEJMoa12 09825

26. van Leeuwen FE, Ng AK. Long-term risk of second malignancy and cardiovascular disease after Hodgkin lymphoma treatment. Hematol Am Soc Hematol Educ Program. (2016) 2016:323-30. doi: 10.1182/ asheducation-2016.1.323

27. Vallerio $P$, Maloberti A, Palazzini M, Occhi L, Peretti A, Nava S, et al. Thoracic radiotherapy as a risk factor for heart ischemia in subjects treated with chest irradiation and chemotherapy and without classic cardiovascular RISK factors. Radiother Oncol. (2020) 152:146-50. doi: 10.1016/j.radonc.2020.07.004

28. Heidenreich PA, Hancock SL, Lee BK, Mariscal CS, Schnittger I. Asymptomatic cardiac disease following mediastinal irradiation. $J \mathrm{Am}$ Coll Cardiol. (2003) 42:743-9. doi: 10.1016/S0735-1097(03)00759-9

29. Groarke JD, Tanguturi VK, Hainer J, Klein J, Moslehi JJ, Ng A, et al. Abnormal exercise response in long-term survivors of Hodgkin lymphoma treated with thoracic irradiation: evidence of cardiac autonomic dysfunction and impact on outcomes. J Am Coll Cardiol. (2015) 65:573-83. doi: 10.1016/j.jacc.2014.11.035

30. Vinik AI, Casellini C, Parson HK, Colberg SR, Nevoret ML. Cardiac autonomic neuropathy in diabetes: a predictor of cardiometabolic events. Front Neurosci. (2018) 12:591. doi: 10.3389/fnins.2018.00591

31. Teng AE, Noor B, Ajijola OA, Yang EH. Chemotherapy and radiationassociated cardiac autonomic dysfunction. Curr Oncol Rep. (2021) 23:14. doi: 10.1007/s11912-020-01013-7
32. Laukkanen JA, Kurl S, Lakka TA, Tuomainen TP, Rauramaa R, Salonen R, et al. Exercise-induced silent myocardial ischemia and coronary morbidity and mortality in middle-aged men. J Am Coll Cardiol. (2001) 38:72-7. doi: 10.1016/S0735-1097(01)01311-0

33. Choi KH, Lee JM, Park I, Kim J, Rhee TM, Hwang D, et al. Comparison of long-term clinical outcomes between revascularization versus medical treatment in patients with silent myocardial ischemia. Int J Cardiol. (2019) 277:47-53. doi: 10.1016/j.ijcard.2018.08.006

34. Mulrooney DA, Nunnery SE, Armstrong GT, Ness KK, Srivastava D, Donovan FD, et al. Coronary artery disease detected by coronary computed tomography angiography in adult survivors of childhood Hodgkin lymphoma. Cancer. (2014) 120:3536-44. doi: 10.1002/cncr.28925

35. Valensi P, Meune C. Congestive heart failure caused by silent ischemia and silent myocardial infarction: diagnostic challenge in type 2 diabetes. Herz. (2019) 44:210-17. doi: 10.1007/s00059-019-4798-3

36. Patsouras A, Farmaki P, Garmpi A, Damaskos C, Garmpis N, Mantas D, et al. Screening and risk assessment of coronary artery disease in patients with type 2 diabetes: an updated review. In Vivo. (2019) 33:1039-49. doi: 10.21873/invivo.11572

37. Donnellan E, Griffin BP, Johnston DR, Popovic ZB, Alashi A, Kapadia SR, et al. Rate of progression of aortic stenosis and its impact on outcomes in patients with radiation-associated cardiac disease: a matched cohort study. JACC Cardiovasc Imaging. (2018) 11:1072-80. doi: 10.1016/j.jcmg.2018.04.019

38. Lindman BR, Clavel MA, Mathieu P, Iung B, Lancellotti P, Otto CM, et al. Calcific aortic stenosis. Nat Rev Dis Primers. (2016) 2:16006. doi: $10.1038 / n r d p .2016 .6$

39. Capoulade R, Clavel MA, Mathieu P, Côté N, Dumesnil JG, Arsenault M, et al. Impact of hypertension and renin-angiotensin system inhibitors in aortic stenosis. Eur J Clin Invest. (2013) 43:1262-72. doi: 10.1111/eci.12169

40. Rassa A, Zahr F. Hypertension and aortic stenosis: a review. Curr Hypertens Rev. (2018) 14:6-14. doi: 10.2174/1573402114666180416161326

41. Donato M, Ferri N, Lupo MG, Faggin E, Rattazzi M. Current evidence and future perspectives on pharmacological treatment of calcific aortic valve stenosis. Int J Mol Sci. (2020) 21:8263. doi: 10.3390/ijms21218263

42. Atkins KM, Bitterman DS, Chaunzwa TL, Williams CL, Rahman R, Kozono DE, et al. Statin use, heart radiation dose, and survival in locally advanced lung cancer. Pract Radiat Oncol. (2021) 11:e459-67. doi: 10.1016/j.prro.2020. 12.006

43. da Silva RMFL. Effects of radiotherapy in coronary artery disease. Curr Atheroscler Rep. (2019) 21:50. doi: 10.1007/s11883-019-0810-x

44. Reed GW, Masri A, Griffin BP, Kapadia SR, Ellis SG, Desai MY. Longterm mortality in patients with radiation-associated coronary artery disease treated with percutaneous coronary intervention. Circ Cardiovasc Interv. (2016) 9:e003483. doi: 10.1161/CIRCINTERVENTIONS.115.003483

45. Chang AS, Smedira NG, Chang CL, Benavides MM, Myhre U, Feng J, et al. Cardiac surgery after mediastinal radiation: extent of exposure influences outcome. J Thorac Cardiovasc Surg. (2007) 133:404-13. doi: 10.1016/j.jtcvs.2006.09.041

46. Crestanello JA, McGregor CG, Danielson GK, Daly RC, Dearani JA, Orszulak TA, et al. Mitral and tricuspid valve repair in patients with previous mediastinal radiation therapy. Ann Thorac Surg. (2004) 78:826-31. doi: 10.1016/j.athoracsur.2004.04.008

47. Brown ML, Schaff HV, Sundt TM. Conduit choice for coronary artery bypass grafting after mediastinal radiation. J Thorac Cardiovasc Surg. (2008) 136:1167-71. doi: 10.1016/j.jtcvs.2008.07.005

48. Wu W, Masri A, Popovic ZB, Lytle BW, Marwick TH, Griffin BP, et al. Long-term survival of patients with radiation heart disease undergoing cardiac surgery: a cohort study. Circulation. (2013) 127:1476-84. doi: 10.1161/CIRCULATIONAHA.113.001435

49. Donnellan E, Masri A, Johnston DR, Pettersson GB, Rodriguez LL, Popovic $\mathrm{ZB}$, et al. Long-term outcomes of patients with mediastinal radiationassociated severe aortic stenosis and subsequent surgical aortic valve replacement: a matched cohort study. J Am Heart Assoc. (2017) 6:e005396. doi: 10.1161/JAHA.116.005396

50. Zafar MR, Mustafa SF, Miller TW, Alkhawlani T, Sharma UC. Outcomes after transcatheter aortic valve replacement in cancer survivors with prior chest radiation therapy: a systematic review and meta-analysis. Cardiooncology. (2020) 6:8. doi: 10.1186/s40959-020-00062-y 
51. Agrawal N, Kattel S, Waheed S, Kapoor A, Singh V. Sharma A, et al. Clinical outcomes after transcatheter aortic valve replacement in cancer survivors treated with ionizing radiation. Cardiooncology. (2019) 5:8. doi: 10.1186/s40959-019-0044-7

52. Ejiofor JI, Ramirez-Del Val F, Nohria A, Norman A, McGurk S, Aranki $\mathrm{SF}$, et al. The risk of reoperative cardiac surgery in radiation-induced valvular disease. J Thorac Cardiovasc Surg. (2017) 154:1883-95. doi: 10.1016/j.jtcvs.2017.07.033

53. Armstrong GT, Oeffinger KC, Chen Y, Kawashima T, Yasui Y, Leisenring W, et al. Modifiable risk factors and major cardiac events among adult survivors of childhood cancer. J Clin Oncol. (2013) 31:3673-80. doi: 10.1200/JCO.2013.49.3205

54. Bhatt AS, Ambrosy AP, Velazquez EJ. Adverse remodeling and reverse remodeling after myocardial infarction. Curr Cardiol Rep. (2017) 19:71. doi: 10.1007/s11886-017-0876-4

55. Galli E, Lancellotti P, Sengupta PP, Donal E. LV mechanics in mitral and aortic valve diseases: value of functional assessment beyond ejection fraction. JACC Cardiovasc Imaging. (2014) 7:1151-66. doi: 10.1016/j.jcmg.2014.07.015

56. Shabbir A, Fan L, Fraser G, Cassar MP, Swinburn J. Quantification of ischemia as a prognostic mandate for coronary revascularization in asymptomatic patients: how much is enough? Crit Pathw Cardiol. (2019) 18:98-101. doi: 10.1097/HPC.0000000000000176

57. Kazak AE, DeRosa BW, Schwartz LA, Hobbie W, Carlson C, Ittenbach RF, et al. Psychological outcomes and health beliefs in adolescent and young adult survivors of childhood cancer and controls. J Clin Oncol. (2010) 28:2002-7. doi: 10.1200/JCO.2009.25.9564

58. Kirchhoff AC, Lyles CR, Fluchel M, Wright J, Leisenring W. Limitations in health care access and utilization among long-term survivors of adolescent and young adult cancer. Cancer. (2012) 118:5964-72. doi: 10.1002/cncr.27537

59. Kaul S, Avila JC, Mehta HB, Rodriguez AM, Kuo YF, Kirchhoff AC. Costrelated medication nonadherence among adolescent and young adult cancer survivors. Cancer. (2017) 123:2726-34. doi: 10.1002/cncr.30648

60. Gujral DM, Lloyd G, Bhattacharyya S. Radiation-induced valvular heart disease. Heart. (2016) 102:269-76. doi: 10.1136/heartjnl-2015-308765
61. Deng G, Liang N, Xie J, Luo H, Qiao L, Zhang J, et al. Pulmonary toxicity generated from radiotherapeutic treatment of thoracic malignancies. Oncol Lett. (2017) 14:501-11. doi: 10.3892/ol.2017.6268

62. Cella L, Liuzzi R, D’Avino V, Conson M, Di Biase A, Picardi M, et al. Pulmonary damage in Hodgkin's lymphoma patients treated with sequential chemo-radiotherapy: predictors of radiation-induced lung injury. Acta Oncol. (2014) 53:613-9. doi: 10.3109/0284186X.2013.850739

63. Giuranno L, Ient J, De Ruysscher D, Vooijs MA. Radiation-induced lung injury (RILI). Front Oncol. (2019) 9:877. doi: 10.3389/fonc.2019. 00877

64. Lestuzzi C, Annunziata MA, Nohria A, Muzzatti B, Bisceglia I, Ewer MS. Cancer patients in cardiology: how to communicate with patients with special psychological needs and manage their cardiac problems in daily clinical practice. J Cardiovasc Med. (2020) 21:286-91. doi: 10.2459/JCM.0000000000000936

Conflict of Interest: The authors declare that the research was conducted in the absence of any commercial or financial relationships that could be construed as a potential conflict of interest.

Publisher's Note: All claims expressed in this article are solely those of the authors and do not necessarily represent those of their affiliated organizations, or those of the publisher, the editors and the reviewers. Any product that may be evaluated in this article, or claim that may be made by its manufacturer, is not guaranteed or endorsed by the publisher.

Copyright $\odot 2021$ Lestuzzi, Mascarin, Coassin, Canale and Turazza. This is an open-access article distributed under the terms of the Creative Commons Attribution License (CC BY). The use, distribution or reproduction in other forums is permitted, provided the original author $(s)$ and the copyright owner(s) are credited and that the original publication in this journal is cited, in accordance with accepted academic practice. No use, distribution or reproduction is permitted which does not comply with these terms. 